\title{
SST Observations of the Agulhas and East Madagascar Retroflections by the TRMM Microwave Imager
}

\author{
Graham D. Quartly and Meric A. Srokosz \\ Southampton Oceanography Centre
}

\author{
[ Submitted to JPO 25th Sept. 2000; Revised: 11th Oct. 2001 ]
}

\begin{abstract}
$\underline{\text { Abstract }}$
The retroflections of the East Madagascar Current and Agulhas Current are complex rapidly-evolving systems, the latter controlling the passage of warm salty water from the Indian Ocean to the Atlantic. The TRMM Microwave Imager (TMI) provides frequent observations of sea surface temperature through clouds, allowing us to monitor the evolution of these systems. We develop a simple feature-tracking system that obviates the need for user intervention, and use its results to guide more focussed studies. In the period 1997-1999, we observe westward progradation of the Agulhas Retroflection (associated with ring shedding) about eight times per year, agreeing with previous estimates from infra-red data, and many rings moving westward or north-westward. However, this behaviour is seen to change in the 2000-2001 time period, with the Agulhas Retroflection occurring further to the east. A few Natal pulses are seen, but cannot be linked conclusively to the spawning of rings due to TMI's limited latitudinal coverage. The majority of features originating at the East Madagascar Retroflection appear to migrate southwestwards. A new observation from the data is that, although the first northward meander of the Agulhas Return Current is constrained by bathymetry, its position does vary intermittently, remaining fixed in a given location for up to six months at a time. Southward propagation of features is noted along two ridges: although eddies have been found before along the eastern slope of the Mozambique Ridge, the new results for the Madagascar Ridge indicate an extra pathway for the eddies. Eddy-like features are also found leading from the Agulhas Return Current back toward the Agulhas Current. The narrow 'corridor' of these features suggests that it is controlled by the gyre recirculation in the southwest Indian Ocean.
\end{abstract}

\section{Introduction}

The Agulhas Current (AC) is the strongest Southern Hemisphere western boundary current, with a narrow well-defined thermal signature along the east coast of South Africa. On leaving the coast at $\sim 25^{\circ} \mathrm{E}$, conservation of potential vorticity causes it to retroflect $\sim 500-600 \mathrm{~km}$ further south, forming the eastwardflowing Agulhas Return Current (ARC), which has significant meanders, partly constrained by the local bathymetry (see Fig. 1). This is an eddy-rich region with Agulhas rings $\sim 200 \mathrm{~km}$ in diameter being shed at the retroflection and large eddies occurring along the ARC (Olson and Evans 1986, Gründlingh 1983, Lutjeharms and Valentine 1988). The AC is fed by the Mozambique Current and the East Madagascar Current (EMC), but there is debate about their relative contributions (de Ruijter et al. 1999a). Indeed, recent in situ observations by de Ruijter et al. (2001) suggest that the Mozambique Current is not itself a permanent feature, but only present intermittently as anticyclonic eddies pass through the Mozambique Channel. Lutjeharms (1988a) shows that south of Madagascar the EMC also exhibits a retroflection. Feed from the EMC to the AC may thus be via a thin remnant adhering to the south coast of Madagascar or by westward movement of eddies shed from this retroflection. Drifter data has shown that the latter may be the case at least some of the time (Lutjeharms, 1988b). Here we look at the new insights that can be gained from TRMM Microwave Imager (TMI) data to aid our understanding of both retroflection systems. Section 2 describes the data and processing; section 3 explains the simple feature-tracking technique and its results, with a more focussed regional analysis given in section 4 . We end with a brief discussion and conclusions. 


\section{TRMM Microwave Imager (TMI): Data and processing}

The TMI is a multi-channel scanning passive microwave radiometer, designed for observing precipitation. However, its $10.7 \mathrm{GHz}$ channel permits the recovery, through non-raining clouds, of sea surface temperature (SST) data. These have been shown to agree well with buoy measurements (Wentz et al., 2000). TRMM's low altitude $(350 \mathrm{~km})$ gives an antenna footprint at $10.7 \mathrm{GHz}$ of $35 \mathrm{~km} \times 60 \mathrm{~km}$ (Kummerow et al., 1998), suitable for detecting mesoscale features. However, SST values close to the coast will be contaminated by the influence of land. We have used daily files of SST gridded at $0.25^{\circ}$ by $0.25^{\circ}$, which are provided by EORC/NASDA (http://www.eorc.nasda.go.jp/TRMM).

The inclination of the TRMM orbit is $35^{\circ}$, so the TMI data only extend as far south as $38^{\circ} \mathrm{S}$, just short of the main region of the Agulhas Retroflection (AR) and mean ARC. The rest of the area of interest (Fig. 1) is observed at least once every day. Because of the satellite's low altitude, the TMI swath does not cover all regions within one day. To minimize errors, especially biases associated with variation in day/night sampling, we composite the data in 6-day averages, as large features will not change greatly in such a period. We form the 6-day averages at intervals of 3 days to make it easier to monitor changes in the spatial arrangements. We then apply a smoothing filter $(\sim 100 \mathrm{~km}$ in diameter $)$ to remove finer scale structure, yet leave the signature of the AC and associated eddy features undiminished. Data from 8th Dec 1997 to 31st Jul. 2001 provide us with 443 composite SST maps, 3 days apart. We apply EOF analysis to characterise and remove the large-scale coherent variations in SST. For example, the first two modes of variation are the mean and seasonal signals. The third and fourth modes principally represent meridional changes in SST to the west of S. Africa, with the fourth mode probably portraying changes in upwelling, in response to changes in winds. Here, we remove the first five EOF modes from the data to make the motion of the smaller scale features clearer. Experiments removing different numbers $(3,4,5)$ of EOFs changes the picture obtained in terms of the fine detail, but do not impact the overall results presented below. Figure 2 illustrates the result of this initial filtering of the data. The top image shows the original SST field for the period 23rd-28th Jan. 1999, and the middle one shows the result of filtering, which removes the mean AC and the Benguela Upwelling. Eddy-like features abound, including a region of enhanced temperature on the edge of the AC (marked by a box). Figure 2c shows the r.m.s. variability of the filtered SST data, with high variability along the coast of S. Africa and Madagascar, and also along the southern and eastern boundaries of the region. There are large areas for which the residual variability is less than $0.4^{\circ} \mathrm{C}$; these indicate regions for which there is little SST variation that is not adequately represented by the first five EOFs. To get a clearer picture of the variations we apply simple feature-tracking and then (in section 4) examine Hovmöller diagrams for selected regions.

\section{Feature-tracking: Method and results}

The filtering produces SST anomalies; clearly non-changing features will have no signal. To track features we find local maxima in the filtered SST field and, using a search box $200 \mathrm{~km}$ square centred on a maximum, examine the immediately preceding and succeeding fields. If a 'significant' feature is found then tracking is continued a further step, using a box centred on the new location. The tracking ends if either the peak falls below $0.4^{\circ} \mathrm{C}$ or it is located on the edge of the box (possibly indicating that tracking has jumped to a larger feature centred outside the box). This is a simple scheme to determine the main propagation directions of features, and so makes no assumption that features will continue to move in the same direction. Olson and Evans (1986) and Goni et al. (1997) noted that Agulhas rings often show sharp changes in trajectory early on in their life. As the feature-tracking is quite simplistic, many of the tracks are short, possibly due to features being 'lost' for a while when their surface signature becomes small. Thus the feature-tracking is only indicative of the direction of motion of the stronger SST anomalies, rather than giving a complete time-history of all events. However, a series of trials with slightly different SST thresholds or tracking strategies produced the same basic results detailed here.

The analysis was performed for both positive anomalies (SST anomaly $\geq 0.4^{\circ} \mathrm{C}$ ) and negative ones (SST anomaly $\leq-0.4^{\circ} \mathrm{C}$ ) and the 250 largest amplitude events of each type are shown in Fig 3. Although many of the tracks are short, the ensemble provides a coherent picture. The tracking for negative anomalies 
is shown so as both to highlight any features with a negative signature and also to act as a contrast to Fig. $3 \mathrm{a}$. Since we are looking at anomalies, a series of cold core eddies (negative anomalies) along a path may lead to the appearance of positive anomalies along that route (effectively due to the gaps between the eddies). It is thus interesting that the negative anomalies do not show the same coherent patterns.

The positive anomalies indicate significant activity to the south of Madagascar. Most of the features head southwards along the Madagascar Ridge and then southwestwards. The track of the positive anomalies ties in with the enhanced SST variability in Fig. 2c. As this is not known to be the route of the EMC after retroflection, it seems likely that these are eddies shed at the retroflection. It was surprising that none appear to make the direct westward progression to the AC as expected from drifter tracks (Lutjeharms, 1988b) and high resolution models (Biastoch and Krauss 1999); their apparent absence may be due to such a path being approximately along an isotherm (see Fig. 2a). Thus such propagating features would produce little by way of SST anomaly.

A large number of features head poleward along the east coast of S. Africa. There are few positive features on the mean axis of the AC; rather most move down the seaward side, where an advected eddy or a large-scale meander of the current can lead to a large positive SST anomaly. This is especially true after leaving the coast, where the mean AC is marked by a strip free of warm anomalies. It is likely that some of these positive anomalies are Natal Pulses, large offshore meanders of the AC. These are intermittent features, extending more than $200 \mathrm{~km}$ from the shore (Gründlingh 1979) and propagating along the coast at approximately $20 \mathrm{~km}$ day $^{-1}$ (Lutjeharms and Roberts 1988, van Leeuwen et al. 2000).

The region to the southwest of S. Africa is where one would expect to find recently spawned Agulhas rings. These usually consist of a pinched off segment of warm water from the AC plus colder entrained water. Should these features move northwards, their cores will be colder than the surrounding region, giving rise to negative anomalies. Agulhas rings may thus be detected as both positive (warm) and negative (cold) anomalies: both Figs $3 \mathrm{a}$ and $3 \mathrm{~b}$ show westward or north-westward movement in this region. Long trajectories should not be expected for either type of feature since it is known that once separated from the AC, ocean-atmosphere heat fluxes will rapidly erode the surface thermal signature (Walker and Mey, 1988).

There are a number of features moving roughly southward around $35.5^{\circ} \mathrm{E}$, which marks the eastern edge of the Mozambique Ridge (see Fig. 1). It is conjectured that these may be cyclonic eddies that are deep enough to be steered by the bathymetry. Although such features have a 'cold core' with lifting of all isotherms below 300m (Gründlingh 1983, 1985) they usually have a positive SST anomaly. On the righthand side of Fig. $3 \mathrm{~b}$ a number of negative anomalies can be seen moving northwestward from $48^{\circ} \mathrm{E}, 36^{\circ} \mathrm{S}$.

As noted above, the analysis was repeated with broader smoothing, and also with different numbers of EOFs removed. Although the tracking of individual features was affected, the overall pattern remained the same. A few of the key regions are examined in greater detail in the next section.

\section{Hovmöller analysis: Regional studies}

Having identified some of the main paths, we examine the time evolution using Hovmöller plots. Figure 4a shows the progression of mean anomalies for the band $34.5^{\circ} \mathrm{E}-36.5^{\circ} \mathrm{E}$. This is a region of above average variability (see Fig. 2c), and appears to be a preferred route for positive anomalies (see Fig. 3a). From $25^{\circ} \mathrm{S}$ to $30^{\circ} \mathrm{S}$ this corresponds to the region just offshore of the AC; whilst further south it represents the eastern flank of the Mozambique Ridge. During the 44-month period there are indications of seven positive anomaly features propagating along this meridional section, albeit that the signals in the later part of the observation period (March 2000 onward) are less distinct than their predecessors. (Although alignments are seen in negative anomalies they are rarely as clear as the positive ones.) In several cases two straight lines are needed to indicate one trajectory, with the 'break point' being near $500 \mathrm{~km}$, which corresponds to a latitude of $34^{\circ} \mathrm{N}$. For events $1,2,4,5 \& 6$ the estimated propagation speeds to the north of $34^{\circ} \mathrm{S}$ have a mean of $12.1 \mathrm{~km} \mathrm{day}^{-1}$ (std. dev. $\left.=2.6 \mathrm{~km} \mathrm{day}^{-1}\right)$. For events $1,2,3,5,6 \& 7$ there is a phase of slower propagation (mean $=3.8 \mathrm{~km} \mathrm{day}^{-1}$, std. dev. $=0.7 \mathrm{~km} \mathrm{day}^{-1}$ ) in the southern region of the section. These slower speeds are similar to the eddy advection velocities of $4-5 \mathrm{~km} \mathrm{day}^{-1}$ noted in this region by Gründlingh $(1983,1985)$. 
To monitor features following the coast, we calculate the mean SST anomaly for each point along the coast using a $\sim 200 \mathrm{~km}$ transect on a bearing of $120^{\circ}$ (see Fig. 2c). The resultant features (Fig. $4 \mathrm{~b}$ ) are intermittent and show significant changes in propagation speed. A few coherent poleward moving features can be seen, with a pair of lines highlighting the events of July 1998 and February 1999. The lines were chosen to indicate a velocity of $20 \mathrm{~km} \mathrm{day}^{-1}$ for the first $1000 \mathrm{~km}$ (the approximate distance from the Natal Bight to a little south of Port Elizabeth, where the AC leaves the coastal confines for deeper waters) and 5 $\mathrm{km} \mathrm{day}^{-1}$ subsequently. These are values from analysis of infra-red data (van Leeuwen et al., 2000), and confirm that some of the features in Figure $4 \mathrm{~b}$ have propagation characteristics consistent with those observed for Natal Pulses. Up to seven poleward-moving positive anomaly features can be seen in Fig. $4 \mathrm{~b}$ in the period up to May 1999. All give rise to a temperature anomaly of $\sim 0.6^{\circ} \mathrm{C}$ when averaged over a 200 $\mathrm{km}$ transect, and maintain this amplitude for most of their $1000 \mathrm{~km}$ journey beyond the Natal Bight. A number seem to originate from much further up the coast. This suggests that these meanders started further north in the Delagoa Bight, although these earlier signals could be migrating eddies which initiate a meander only on reaching the shallow shelf of the Natal Bight (de Ruijter et al., 1999b). The signals are not so coherent after May 1999. Two further propagating features are marked, but they are weaker than their predecessors, and do not travel to the end of the specified path. Using TOPEX/Poseidon altimeter data, we made a brief examination of the sea surface height ( $\mathrm{ssh}$ ) averaged near $29^{\circ} \mathrm{E}, 32^{\circ} \mathrm{S}$. The small circles at the $400 \mathrm{~km}$ mark in Fig. 4b indicate times when the ssh was significantly lower at that location compared to elsewhere in that region. (Van Leeuwen et al. (2000) have shown that a Natal Pulse should lead to a local reduction in ssh.) Of the ten ssh features marked, six lie close to the lines deduced from TMI SST data, and two others correspond to positive SST anomalies which are not propagating.

The dashed lines on Fig. 4b are mainly to emphasise the features, with the slopes of the lines corresponding to propagation speeds. Clearly some of the features are not represented well by a single straight line. For the coastal section between 0 and $900 \mathrm{~km}$ from Natal Bight, the derived propagation speeds range between 13 and $55 \mathrm{~km}$ day $^{-1}$. The maximum value (from case $\mathrm{G}$ ) is much higher than reported elsewhere, and is probably a result of attempting to match it to the positive anomalies north of the Natal Bight. The median of the nine measurements is $25 \mathrm{~km} \mathrm{day}^{-1}$, which is close to the value of $20 \mathrm{~km} \mathrm{day}^{-1}$ noted by Lutjeharms and Roberts (1988). Lutjeharms et al. (2001) have suggested that by $26-28^{\circ} \mathrm{E}$ the speed of Natal Pulses may be as slow as $11 \mathrm{~km} \mathrm{day}^{-1}$. Lutjeharms and Roberts (1988) also note that the speed reduces to around $5 \mathrm{~km} \mathrm{day}^{-1}$ upon leaving the coast at Port Elizabeth (approximately $900 \mathrm{~km}$ from the Natal Bight). We have noted that features A, B and E do show a slower speed after there, but it is hard to estimate the values over such a relatively short extent.

The southern limit of TMI's coverage means it is impossible to observe ring shedding from the Agulhas Retroflection directly. The best we can do is monitor the western edge of the AC as it disappears from the frame of view. We take the original smoothed dataset including the mean signal, and calculate the zonal gradient at $38^{\circ} \mathrm{S}$ to highlight the sharp change. Fig. 4c shows repeated westward progradation, with 17 possible events in the first two years. If all are separate events, this gives an average close to the $9 \mathrm{yr}^{-1}$ found by Lutjeharms and van Ballegooyen (1988) from infra-red data. However, some 'events' are not completely distinct from their neighbors in time; a lower bound on the number of events is $6 \mathrm{yr}^{-1}$, a value Feron et al. (1992) found from altimetry. The disparity between estimates may be due to anomalous or partial westward progradation of the AR, but with the release of an eddy to the south, which is subsequently advected east rather than transporting Indian Ocean water into the Atlantic. No clear progradation is observed during February to September 2000; van Leeuwen et al. (2000) noted a 6-month period of inactivity in late 1993. Thereafter there appears to be one clear event followed again by another 6-month "quiet" period until the end of April 2001. The mean progradation rate observed in the TMI data is $11.9 \pm 2.3 \mathrm{~km}^{-1}$ day , agreeing with Lutjeharms and van Ballegooyen's (1988) $12 \mathrm{~km}$ day $^{-1}$.

The observations (Fig. 4) clearly show that something unusual occurred during 2000-2001. Features along all three of these sections either disappeared or had a much weaker signature. Towards the end of 2000 there is a significant change in the behaviour of the AC system. This is not entirely clear in the data shown in Fig. 4, but by examining an animation of TMI SST pictures we have found that during the period 
October 2000 - March 2001 the Agulhas Current appears to leave the coast in a more southerly direction. As a result the feature seen in Fig. $4 \mathrm{c}$ at $\sim 26^{\circ} \mathrm{E}$ propagating towards $\sim 20^{\circ} \mathrm{E}$, during December 2000 to March 20001, is associated with the AC rather than with the meander in the ARC as is the case earlier in the observations. It is unclear what has caused this change in the circulation of the AC system. It is known that if the $\mathrm{AC}$ is stronger it will tend to leave the coast in a more southerly direction, while if it is weaker it will tends to follow the topography in a more south-westerly direction (see discussion in Quartly and Srokosz, 1993, and references therein).

The changed location of the AC during late 2000 may explain why the possible Natal Pulse feature $\mathrm{H}$ appears to die out; the main axis of the current directs it away from the specified section used in this Hovmöller analysis (Fig. 2c) The TMI analysis does not reveal a clear correspondence between Natal Pulses and ring shedding as noted by van Leeuwen et al. (2000), using altimeter and infra-red observations. However, it is possible that feature $\mathrm{H}$ helps instigate the return of the AC to its normal path.

We observed no clear Natal Pulse during June 1999 to June 2000, and only one clear progradation of the Agulhas Retroflection during January 2000 to April 2001. Van Leeuwen et al. (2000) commented on an absence of Natal Pulses in the second half of 1993, and Schouten et al (2000) found only one clear ringshedding event during each of September 1993 to March 1994 and August 1995 to April 1996. These observations are suggestive of the idea that El Niño activity may have a delayed effect on the Agulhas Current region (Schouten et al., 2001); the effects observed here being linked in some way to the 1997/98 event.

Near $26^{\circ} \mathrm{E}$ there is a sharp change between negative and positive gradients, representing the centre of a meander in the ARC. This feature is emphasised by the dotted lines, and the observations indicate that it is not completely fixed, despite the strong bathymetric forcing (the Agulhas Plateau is centred at $26^{\circ} \mathrm{E}$ ). The four intervals marked correspond to the meander being centred at $26.6^{\circ} \mathrm{E}, 25.8^{\circ} \mathrm{E}, 26.4^{\circ} \mathrm{E}$ and finally $25.0^{\circ} \mathrm{E}$. Modelling studies by Lutjeharms and van Ballegooyen (1984) indicate that changes in bottom velocity could produce slight adjustments in the path of the ARC around the Agulhas Plateau, but what is new here is that we have observed that the position usually remains fixed for six or more months at a time. This meander around the Agulhas Plateau is not present during October 2000 to March 2001, due to the AC adopting a more southerly route.

A more detailed inspection of the behaviour of this loop affords two other observations. First, the occasional re-establishments of stability usually involve movement to the east (e.g. Nov. 1998, Jun. 1999, Jun. 2000), i.e. they have been preceded by an abrupt change which left the loop to the west of its stable position. The second point of interest is that within the long periods of stable loop position (e.g. Aug. 1999 to Apr. 2000) there are many small-scale variations in the loop position, with a timescale of $\sim 20$ days. These may indicate some resonance period about the stable position. This would be interesting to investigate further, however the oscillations are not much larger than the resolution of the TMI, so the use of additional datasets would be necessary.

\section{Conclusions}

The ability to observe SST through clouds will revolutionise the study of rapidly-evolving systems (Wentz et al., 2000). We have examined the TMI data for two very active ocean systems: the Agulhas and East Madagascar Retroflections. The region is notorious for the cloud cover impact on infra-red observations; van Leeuwen et al. (2000) could not observe the sea surface for 50 days at a time. As the TMI SST fields are spatially complete we have been able to automate the detection and tracking of features, whereas infra-red analyses through patchy cloud have needed human subjective interpretation to detect (Lutjeharms and van Ballegooyen, 1988) and monitor features (van Leeuwen et al., 2000). The TMI analysis shows a number of positive anomalies moving poleward along the east coast of S. Africa, with propagation characteristics similar to those of Natal pulses. Although the Agulhas Retroflection itself was outside of the TMI's coverage, we can see convincing westward progradations of the current, with $\sim 8$ events per year, consistent with other estimates, during the period December 1997 to March 2000. Thereafter, we have 
observed a change in the behaviour of the Agulhas Retroflection, with the retroflection occurring further to the east. This may be due to a strengthening of the Agulhas Current, possibly associated with changes in Indian Ocean circulation (see discussion in Quartly and Srokosz, 1993) and requires further investigation (beyond the scope of this paper). Many Agulhas rings appear to show up as warm or cold anomalies, drifting to the west or northwest. However, they cannot be tracked for long because of the rapid loss of surface thermal signature (Walker and Mey, 1988). The new observations of the East Madagascar Retroflection are intriguing in that the majority of warm features appear to head south and then southwest, although this could be because those going west have minimal SST anomaly and cannot be detected by the methods used here.

Finally, we have made new observations of the position of the topographically controlled meander in the ARC at $\sim 26^{\circ} \mathrm{E}$ and found that its position varies in an unexpected manner; remaining fixed for months and then shifting abruptly to the east or west by $\sim 0.5^{\circ}$ or more. There also appears to be small-scale variability in this feature on a timescale of $\sim 20$ days. Both of these findings warrant further investigation.

This paper has demonstrated the many different insights into the circulation in this region that can be obtained from TMI data alone, including observations of some unexpected and as yet unexplained changes in the AC and ARC. Naturally, a clearer picture would be obtained if these were combined with altimetry. This would help to decide whether the features along the Mozambique Ridge are indeed cold core cyclonic eddies with a warm cap, and also aid in the interpretation and tracking of the near-coastal features. This is the subject of future work.

\section{Acknowledgements}

We are grateful to EORC/NASDA for the provision of the TMI SST data.

\section{$\underline{\text { References }}$}

Biastoch A., and W. Krauss, 1999: The role of mesoscale eddies in the source regions of the Agulhas Current, J. Phys. Oceanogr. 29, 2303-2317.

de Ruijter W. P. M., A. Biastoch,, et al. 1999a: Indian-Atlantic interocean exchange: Dynamics, estimation and impact, J. Geophys. Res. 104, 20 885-20 910.

de Ruijter W. P. M., P. J. van Leeuwen, and J. R. E. Lutjeharms, 1999b: Generation and evolution of Natal Pulses: Solitary meanders in the Agulhas Current, J. Phys. Oceanogr. 29, 3043-3055.

de Ruijter W. P. M., H. Ridderinkhof, J. R. E. Lutjeharms, M. W. Schouten, and C. Veth. 2001: Observations of the flow in the Mozambique Channel, accepted by Geophys. Res. Lett.

Feron R. V. C., W. P. M. de Ruijter. and D. Oksam, 1992: Ring shedding in the Agulhas Current system, , J. Geophys. Res. 97, 9467-9477.

Goni G. J., S. L. Garzoli, A. J. Roubicek, D. B. Olson, and O. B. Brown, 1997: Agulhas ring dynamics from TOPEX/POSEIDON satellite altimeter data, J. Mar. Res. 55, 861-883.

Gründlingh M. L., 1979: Observation of a large meander in the Agulhas Current, J. Geophys. Res. 84, 37763778.

Gründlingh M. L,. 1983: Eddies in the Southern Indian Ocean and Agulhas Current, in "Eddies in Marine Science". A. R. Robinson, Springer-Verlag: 245-264.

Gründlingh M. L., 1985: An intense cyclonic eddy east of the Mozambique Ridge, J. Geophys. Res. 90, 7163-7167.

Kummerow C., W. Barnes, K. Toshiaki, J. Shiue, and J. Simpson, 1998: The Tropical Rainfall Measuring Mission (TRMM) sensor package, J. Atmos. Oceanic Tech. 15, 809-817.

Lutjeharms J. R. E., 1988a: Remote sensing corroboration of retroflection of the East Madagascar Current, Deep-Sea Res. 35, 2045-2050.

Lutjeharms J. R. E., 1988b: On the role of the East Madagascar Current as a source of the Agulhas Current, S. African J. Sci. 84, 236-238.

Lutjeharms J. R. E., O. Boebel, P. C. F. van der Vaart, W. P. M. de Ruijter, T. Rossby, and H. L. Bryden, 2001: Evidence that the Natal Pulse involves the Agulhas Current to its full depth, Geophys. Res. Lett. (to appear). 
Lutjeharms J. R. E., and H. R. Roberts, 1988: The Natal Pulse: An extreme transient on the Agulhas Current, J. Geophys. Res. 93, 631-645.

Lutjeharms J. R. E., and H. R. Valentine, 1988: Eddies at the subtropical convergence south of Africa, $J$. Phys. Oceanogr. 18 761-774.

Lutjeharms, J. R. E., and R. C. van Ballegooyen, 1984: Topographic control in the Agulhas Current system, Deep-Sea Res. 31, 1321-1337.

Lutjeharms J. R. E., and R. C. van Ballegooyen, 1988: The Retroflection of the Agulhas Current, J. Phys. Oceanogr. 18, 1570-1583.

Olson, D. B, and R. H. Evans, 1986: Rings of the Agulhas Current, Deep-Sea Res. 33, 27-42.

Quartly, G. D., and M. A. Srokosz, 1993: Seasonal variations in the region of the Agulhas Retroflection: studies with Geosat and FRAM, J. Phys. Oceanogr. 23, 2108-2124.

Schouten, M. W.., W. P. M. de Ruijter, P. J. van Leeuwen, and J. R. E. Lutjeharms, 2000: Translation, decay and splitting of Agulhas rings in the southeastern Atlantic Ocean, J. Geophys. Res. 105, 2191321925.

Schouten, M. W.., W. P. M. de Ruijter, P. J. van Leeuwen, and H. A. Dijkstra, 2001: A teleconnection between the equatorial and southern Indian Ocean, (submitted)

Stramma L., and J. R. E. Lutjeharms, 1997: The flow field of the subtropical gyre of the South Indian Ocean, J. Geophys. Res. 102, 5513-5530.

van Leeuwen P. J., W. P. M. de Ruijter, and J. R. E. Lutjeharms, 2000: Natal pulses and the formation of Agulhas rings, J. Geophys. Res. 105, 6425-6436.

Walker N. D. and R. D. Mey, 1988: Ocean/atmosphere heat fluxes within the Agulhas Retroflection region, J. Geophys. Res. 93, 15 475-15 483.

Wentz F. J., C. Gentemann, D. Smith, and D. B. Chelton, 2000: Satellite measurements of sea surface temperature through clouds, Science 288, 847-850.

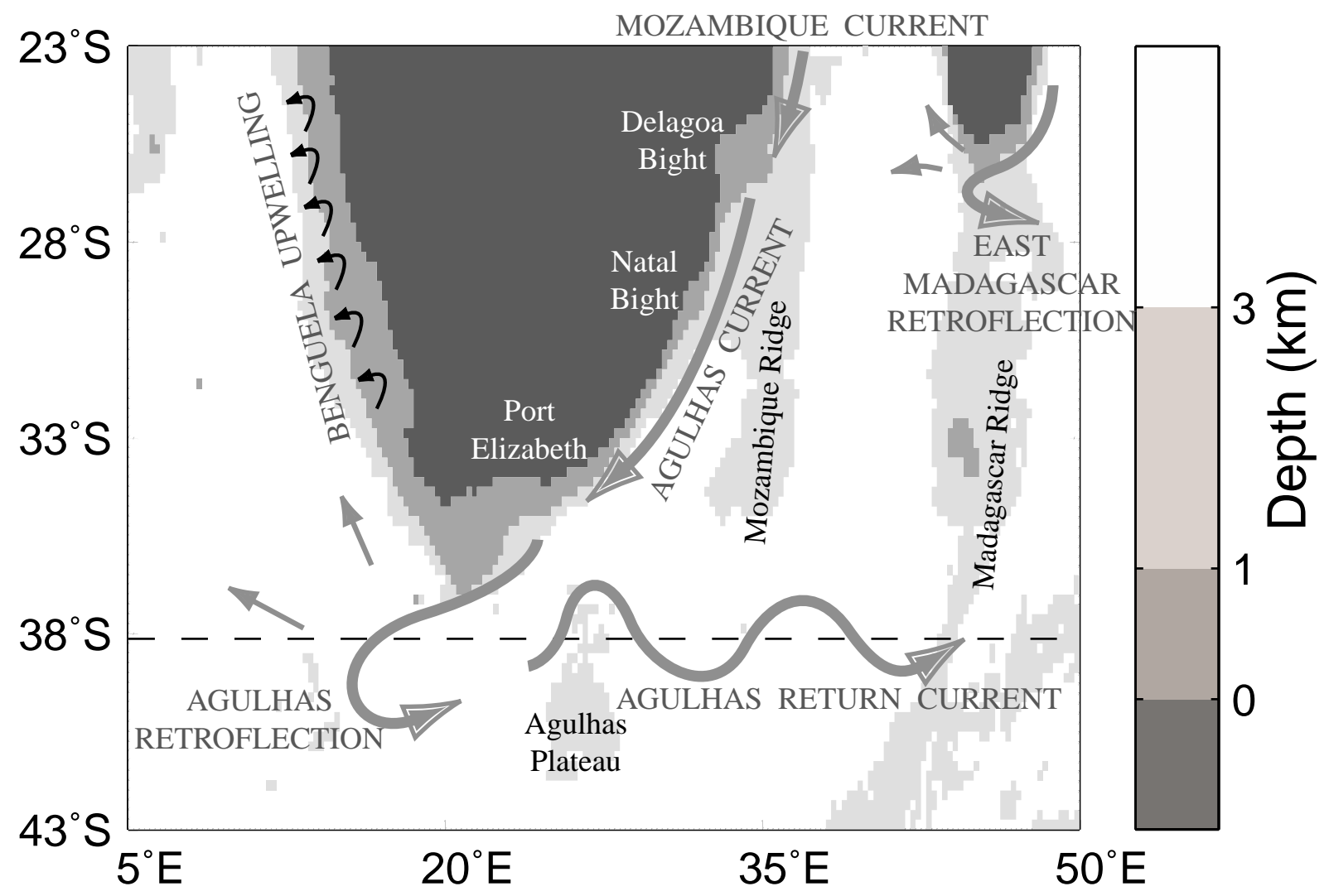

Fig. 1 : Schematic of Agulhas Current System, with the key bathymetric features marked. 

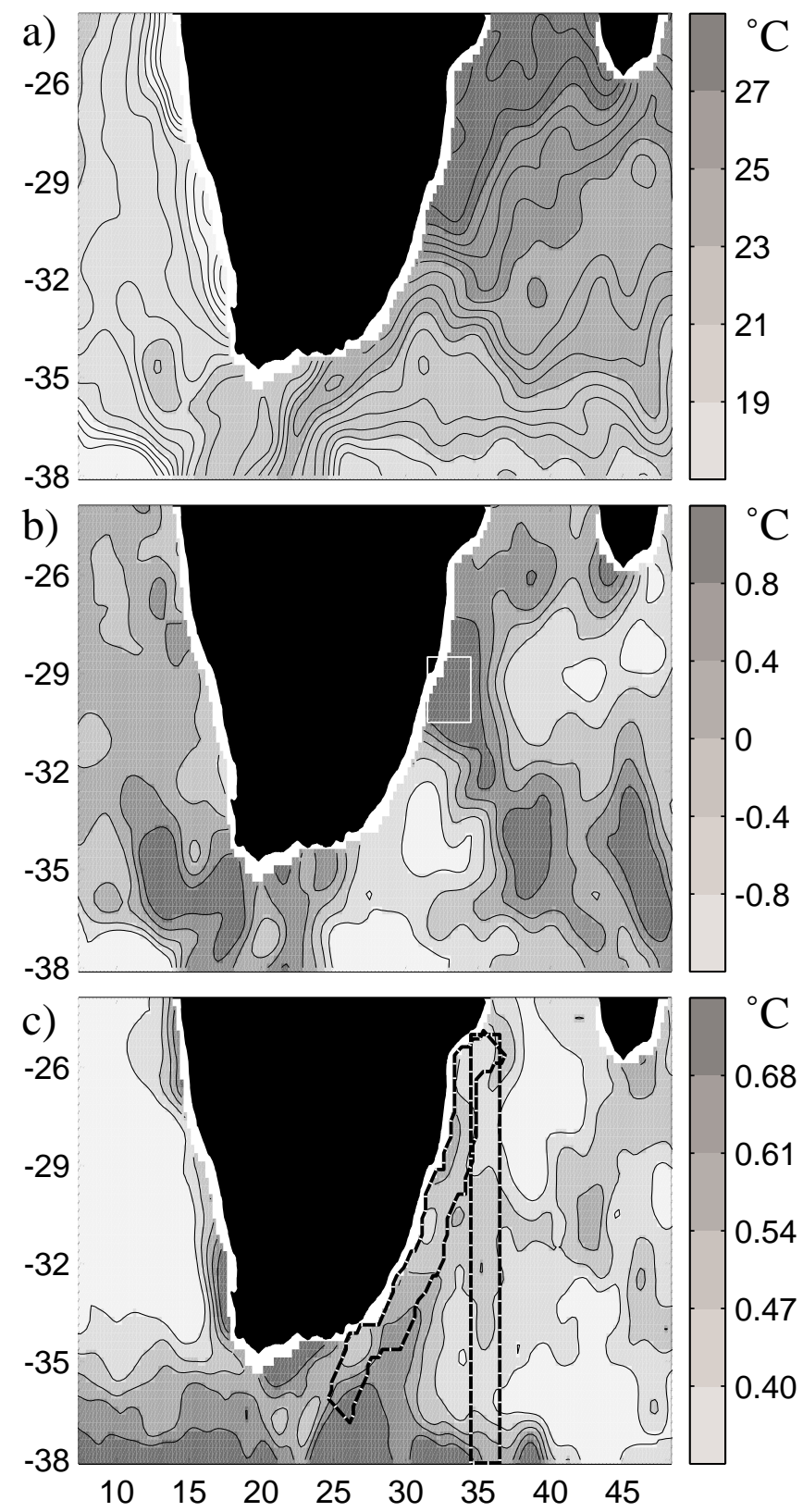

Fig. 2 : a) Smoothed SST field for 23rd-28th Jan. 1999, b) Same field after 5 EOFs removed, c) R.m.s. variability of SST field after the first 5 EOFs have been removed. (The regions with dashed borders are discussed in section 4.) 

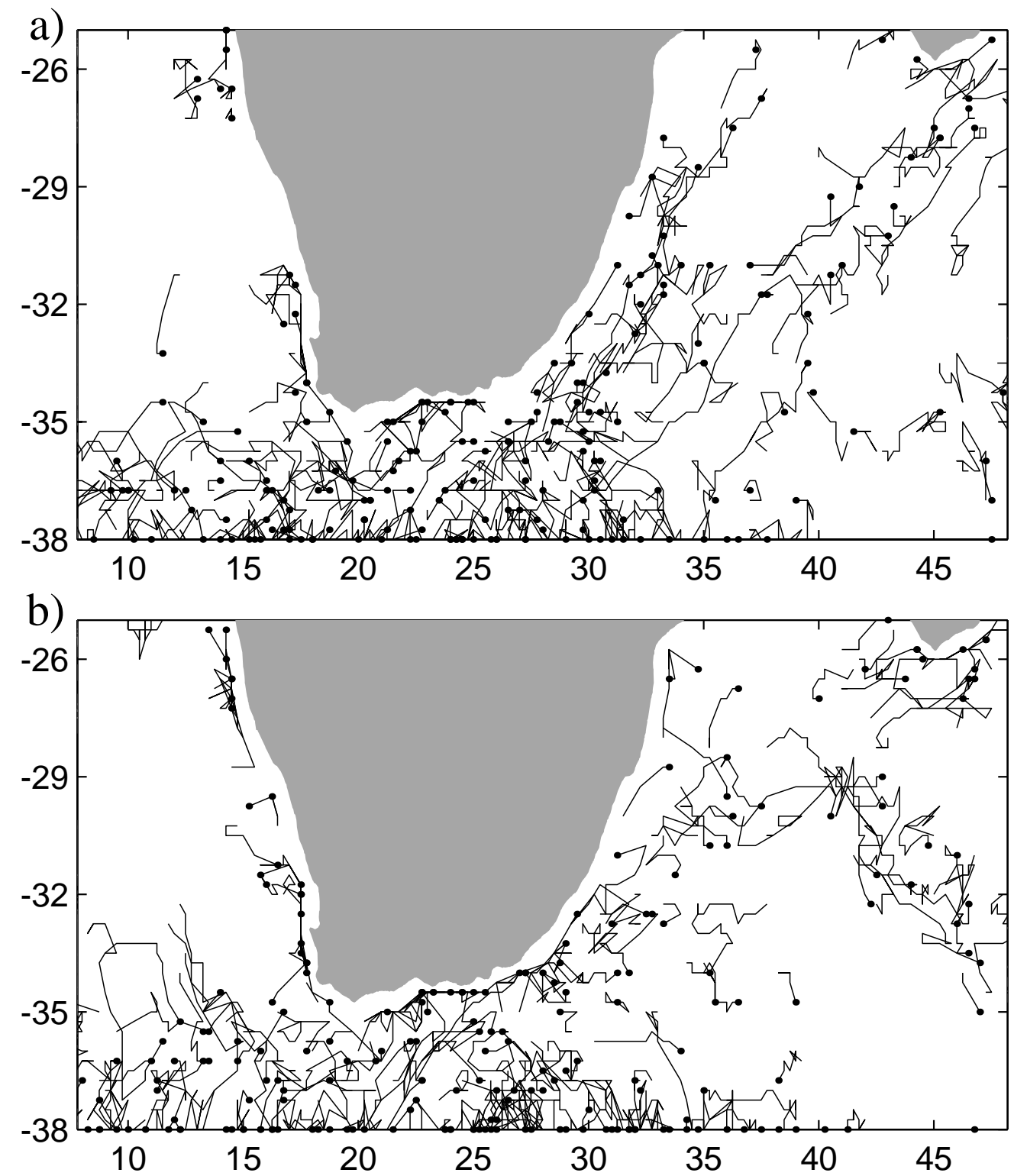

Fig. 3 : a) Tracks of 250 features that maintain an SST anomaly of at least $0.4^{\circ} \mathrm{C}$ for 20 days or more. (A dot marks the start of each track.) b) The same for anomalies below $-0.4^{\circ} \mathrm{C}$. 

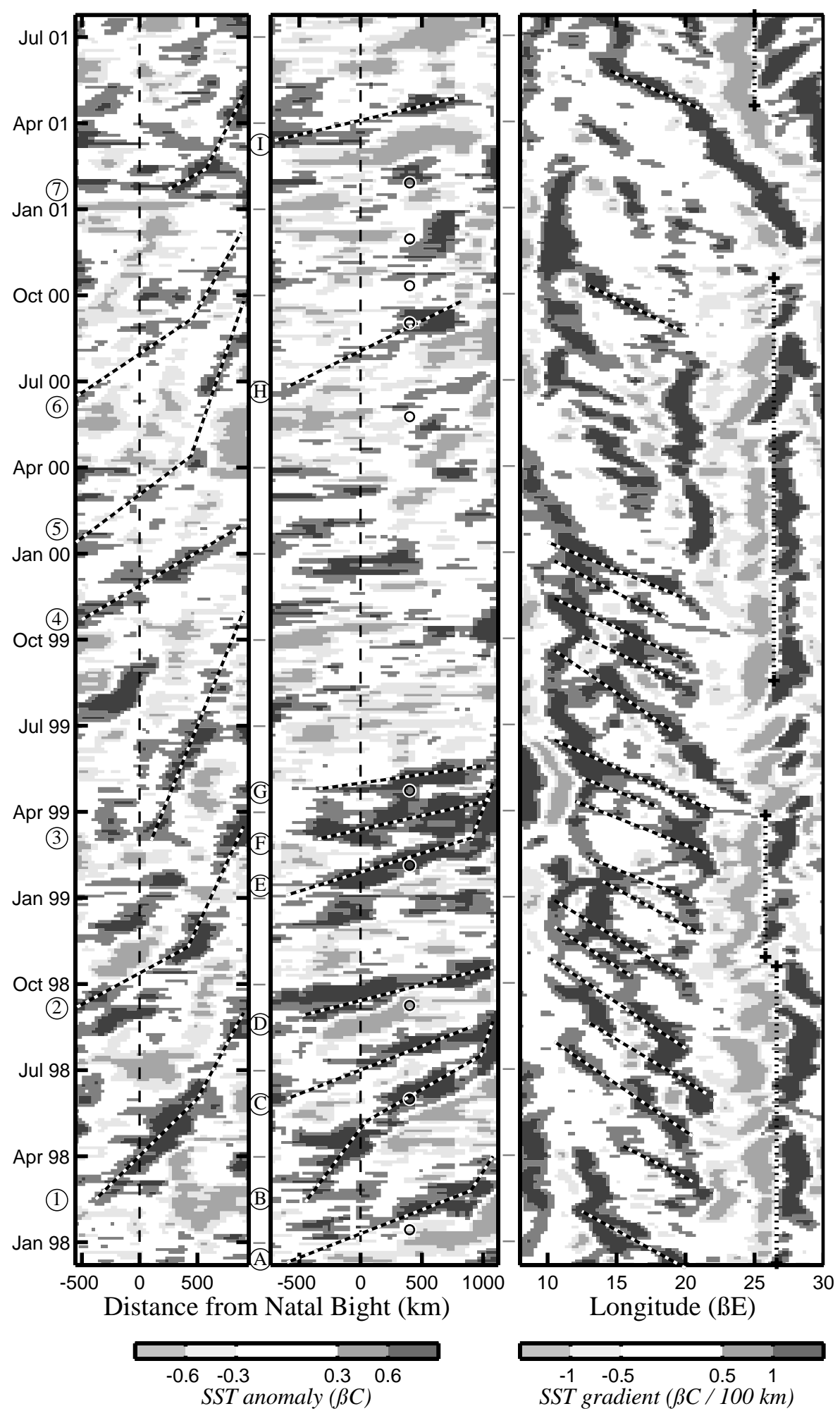

Fig. 4 : a) Hovmöller diagram of mean SST anomaly between $34.5^{\circ} \mathrm{E}$ and $36.5^{\circ} \mathrm{E}$. Dashed lines indicate seven probable events, with circled number on left axis. (The abscissa give the distance from the Natal Bight at $29.5^{\circ} \mathrm{S}$ ). b) Hovmöller diagram of mean anomaly in coastal section marked on Fig. 2c. Circled letters on left of axis refer to the nine highlighted events discussed in the text. The circles denote sea surface depressions observed at $29^{\circ} \mathrm{E}, 32^{\circ} \mathrm{S}$ along the coast. (Abscissa is distance from the Natal Bight, with Port Elizabeth, where the mean current leaves the shore, being $\sim 900 \mathrm{~km}$ along coast) c) Hovmöller diagram of zonal gradient of SST at $38^{\circ} \mathrm{S}$. Dashed lines emphasise possible progradations of the AR; the dotted lines indicate the position of the first cold loop of the ARC. 